OPEN ACCESS

Edited by:

Phil Renforth,

Heriot-Watt University,

United Kingdom

Reviewed by:

Luca Riboldi,

SINTEF, Norway

Charithea Charalambous, Heriot-Watt University,

United Kingdom

*Correspondence:

Graham B. Wenz

gwenz@mosaicmaterials.com

tThese authors have contributed equally to this work and share first authorship

Specialty section

This article was submitted to Negative Emission Technologies, a section of the journal Frontiers in Climate

Received: 30 September 2021 Accepted: 17 December 2021

Published: 04 February 2022

Citation:

Husk JC and Wenz GB (2022) Inside-Out: Driving Down Direct Air Capture Costs With High-Efficiency Adsorbents. Front. Clim. 3:787500.

doi: $10.3389 /$ fclim.2021.787500

\section{Inside-Out: Driving Down Direct Air Capture Costs With High-Efficiency Adsorbents}

\author{
Jason C. Husk ${ }^{\dagger}$ and Graham B. Wenz ${ }^{*+}$ \\ Mosaic Materials, Inc., Alameda, CA, United States
}

As carbon emissions continue to grow, removing carbon dioxide $\left(\mathrm{CO}_{2}\right)$ from the atmosphere will be necessary to curb the impact of climate change, with the need to remove over a billion tons of $\mathrm{CO}_{2}$ in the next decade. Direct air capture (DAC) is a promising technology for removing atmospheric carbon dioxide, with a handful of systems deployed around the globe. As currently deployed, however, tens of millions of these systems are needed to address current and historic emissions, which means creating an industry the size of the auto industry-along with consuming the associated resources - within the next decade. Improving DAC processes via scale is not enough; focusing on breakthroughs in sorbent performance is needed to reduce the number of systems and sheer volume of resources needed to rapidly bring DAC to the scales required to prevent further climate change. There are roles for government, corporations, and the carbon removal industry to play in enabling infrastructure, increasing demand, and creating clarity to accelerate deployment of DAC and, more broadly, carbon dioxide removal technologies.

Keywords: separations, adsorbent, $\mathrm{CO}_{2}$, infrastructure, carbon capture, climate change

\section{INTRODUCTION}

There is little doubt that carbon dioxide emissions into the atmosphere are contributing to climate change. The latest IPCC report outlines the need to not just curb emissions, but to also actively remove carbon dioxide $\left(\mathrm{CO}_{2}\right)$ from the atmosphere using a number of carbon dioxide removal (CDR) solutions (IPCC, 2021). The amount of $\mathrm{CO}_{2}$ to remove from the atmosphere is immensethe IPCC estimates that to limit global warming to under $2^{\circ} \mathrm{C}$, globally we will need to pull one billion tons of $\mathrm{CO}_{2}$ from the atmosphere by 2025, 10 billion tons by 2050, and 100 billion tons by the turn of the century (IPCC, 2021). With many countries currently falling short of their Paris Agreement targets, the ability to meet IPCC emissions targets in time to address climate change is dwindling (UNFCCC, 2021). Even if the global community was able to immediately arrest all $\mathrm{CO}_{2}$ emissions, the current concentration of atmospheric $\mathrm{CO}_{2}$, peaking at $420 \mathrm{ppm}$, is still about 140 ppm above pre-Industrial Revolution levels (NOAA, 2021). That means with no further emissions, there are still $\sim 300$ billion tons of $\mathrm{CO}_{2}$ to remove from the atmosphere (LBNL, 2021). And given there is no way today to completely stop $\mathrm{CO}_{2}$ emissions, with $\mathrm{CO}_{2}$ removal needed at scales this immense, a number of $\mathrm{CDR}$ solutions will need to be deployed to curb the growing $\mathrm{CO}_{2}$ threat.

One promising CDR solution which has the potential to be deployed globally is direct air capture (DAC) (Beuttler et al., 2019). DAC is achieved by processing ambient air through a contactor 
where $\mathrm{CO}_{2}$ interacts with a solid or liquid sorbent which separates the $\mathrm{CO}_{2}$ from the air and allows purified air to exit back into the atmosphere. The $\mathrm{CO}_{2}$ is then desorbed for sequestration or for subsequent utilization by the expanding Carbon-to-Value $(\mathrm{C} 2 \mathrm{~V})$ industry, which is focused on replacing petrochemical sources of carbon by transforming $\mathrm{CO}_{2}$ into useful chemicals, fuels, and other end products. But the growing number of $\mathrm{C} 2 \mathrm{~V}$ companies are dependent on finding an efficient and low-cost source of $\mathrm{CO}_{2}$ to feed their processes (IEA, 2019). Sequestration is equally dependent on these efficient, low-cost sources of $\mathrm{CO}_{2}$, as lower cost DAC systems will accelerate global adoption and deployment of this critical CDR solution.

\section{BUILDING THE NEXT MEGA-INDUSTRY}

One DAC-focused company who has garnered attention recently is Climeworks, who has recently commissioned their Orca DAC system in Iceland capable of capturing 4,000 tons of $\mathrm{CO}_{2}$ each year (Climeworks, 2021). This is an excellent start to addressing this issue, however it brings the global DAC removal capacity to $\sim 11,300$ tons of $\mathrm{CO}_{2}$ per year (Carbon 180, 2021). Looking at the Orca system specifically, however, in light of the IPCC removal goals, the world will need to deploy 250,000 of these systems to hit 2025's one billion ton removal goal. To remove the 40 billion tons per year the globe currently emits, 10 million systems need to be deployed. To remove $\mathrm{CO}_{2}$ back to pre-industrial levels, a stunning 75 million systems will be necessary. For perspective, the entire US auto industry produces 10 million cars each year (US Department of Transportation, 2021). While not all $\mathrm{CO}_{2}$ will be removed via DAC, the supply chain and financial challenges associated with growing from today's scale to the scale required for even a million systems are enormous. While not an intractable problem, DAC will need to become an industry the size of automobile manufacturers or of oil and gas companies, which took over a century to reach their current scales (Peters, 2021).

The world does not have the luxury to wait a century to allow the DAC industry to reach these scales-we have a decade or two to get there. Most companies in the DAC space are small companies and start-ups - they have neither the reach nor the leverage to build a global supply chain at the scales required. Even with the support of government financing and strategic partnerships, such as the 1PointFive collaboration between Oxy Low Carbon Ventures and Carbon Engineering, constructing entirely new global supply chains to feed DAC at the scales needed will be a long, time consuming, and expensive process (Carbon Engineering, 2020). In addition, there are real concerns around the carbon emissions associated with manufacturing at this scale, concerns around land use for this size and number of systems, and concerns about the amount of energy required to operate this many systems (Leibling et al., 2021). While the learning-by-doing approach inherent in Wright's Law will inevitably reduce cost and improve efficiency, without a stepchange in technology, we are limited in improvements by the curve set using today's systems (Wright, 1936).

To this end, leading solid-sorbent DAC technology developers Global Thermostat and Climeworks are adopting a "modular" approach where smaller sized (e.g., 50-4,000 tons per year) sized devices are the repeat unit in a large-scale DAC deployment to leverage gains in manufacturing scale (Carbon180, 2021). However, unless alternative solutions can be found to improve DAC performance and eliminate the need to build and operate tens of millions of systems, we may very well be stuck waiting for the technology to reach scale organically. Fortunately, there is an emerging technology solution which can have a massive impact on reducing the scale of DAC systems-high capacity, high efficiency sorbents that improve DAC system performance and drive down DAC costs.

\section{STEP-CHANGE IN SEPARATIONS PERFORMANCE}

Separations are ubiquitous in industrial processes, consuming more than $10 \%$ of the world's energy (Sholl and Lively, 2016). For example, most of the cost and complexity of a hydrocracking facility is a result of the downstream separations needed to overcome the inefficiencies in catalyst selectivity and conversion. Similarly, today's carbon capture systems are primarily designed to overcome inefficiencies in the $\mathrm{CO}_{2}$ separation technology at the heart of the process. While both liquid and solid-sorbent based technologies are being developed for DAC, the relatively low mass transfer rates between gas-liquid interfaces in liquidbased systems necessitate the use of contactors with large surface areas. Furthermore, liquid-based DAC systems consume significant quantities of water making deployment in arid or resource-limited areas challenging (Keith et al., 2018; NASEM, 2019). The intrinsic porosity of solid adsorbents can overcome these limitations and should allow solid sorbent systems to outperform liquid-based systems due to inherently superior gas-solid mass transfer characteristics. Therefore, the following discussion will focus on solid sorbent-based technologies for improving DAC performance.

Leading companies in the CDR arena, and specifically within DAC, have taken the important first step of designing first generation processes and integrating sorbent materials into these processes. However, the solid adsorbents used in current DAC systems lack the ability to capture large quantities of $\mathrm{CO}_{2}$ from ambient air because of their capacity limitations. A recent report by the National Academies of Science, Engineering, and Medicine estimated that the sorbent will account for $80 \%$ of all DAC costs (NASEM, 2019). Similarly, the Energy Futures Initiative notes that " $[\mathrm{DAC}]$ capital costs are dominated by the sorbent material... Other components are correspondingly less important to address unless and until sorbent material costs can be substantially reduced" (Energy Futures Initiative, 2019). Clearly a significant improvement in sorbent performance is needed to drive down the cost of DAC.

Mosaic Materials is focused on developing metal-organic framework (MOF) solid-sorbents for gas separations. Specifically, Mosaic has been developing amine-appended MOFs which display high capacities under dilute $\mathrm{CO}_{2}$ conditions like ambient air (McDonald et al., 2012, 2015). Furthermore, owing to the cooperative chemisorption mechanism unique 
to this sorbent class they demonstrate high selectivity for $\mathrm{CO}_{2}$ over other components, resulting in low co-adsorption of other components (McDonald et al., 2012). Pushing sorbent performance has been Mosaic Materials' focus, addressing the cost and scale issues of DAC from the heart of the system, i.e., the sorbent material.

The cost of DAC is driven largely by $\mathrm{CO}_{2}$ throughput, given the relatively low concentration of $\mathrm{CO}_{2}$ in the atmosphere. To maximize $\mathrm{CO}_{2}$ throughput, there are two alternatives-move more air (process improvements) or capture more $\mathrm{CO}_{2}$ (sorbent improvements). Given the low capacities of current sorbents, going after process improvements first has been the better path, and one which leading companies have pursued to date. Once a process is designed, however, the system will have a stringent operating window. As such, future "drop-in" sorbents will be subject to those operating windows or require a significant process redesign to leverage technology advantages. Now that sorbents with much higher capacities are being commercialized, it is critical to consider material performance, and subsequent process conditions to optimize material performance, in tandem with process design. Optimizing the material-process interface is critical to utilizing both aspects of a separation system to their fullest to reduce the cost of DAC.

To significantly reduce the cost of DAC and break the $\$ 200 /$ ton $\mathrm{CO}_{2}$ captured price point, below the current combined pricing of \$250 from California's LCFS and Federal 45Q tax credits, sorbent material efficiency must be increased. We believe there are three key approaches to doing so: (1) reduce the cost of manufacturing materials, (2) increase the cyclic stability (reduce degradation) of materials, and (3) increase the capacity of materials. Herein, we assume that at the scales necessary for global $\mathrm{CO}_{2}$ level reduction that sorbent manufacturing costs will come down to the same relative level regardless of technology provided no exotic or rare-earth components are needed; therefore, it is demonstrative to focus on the amount of $\mathrm{CO}_{2}$ a sorbent material is projected to capture over its useful life. Our preliminary estimates, in conjunction with open literature values suggest that current sorbent technologies capture around $130 \mathrm{~kg} \mathrm{CO}$ captured/kg sorbent over its useful life (Deutz and Bardow, 2021). The NASEM report estimates, in their moderate cases, anywhere between 220 and $580 \mathrm{~kg} \mathrm{CO}$ captured/kg sorbent material in its useable lifetime (NASEM, 2019).

Our internal analyses and models for DAC costs indicate that of the three approaches to reducing DAC costs, the most effective strategy for drastically reducing these costs is increasing adsorbent capacity. Doubling adsorbent capacity is equivalent to halving materials manufacturing costs or doubling material lifetime, and has the additional benefits of also lowering the capital expenditures (CapEx) and operating expenditures (OpEx) of a DAC system. Mosaic has demonstrated the performance of materials at and above the "best case" NASEM scenario of $1.5 \mathrm{~mol} / \mathrm{kg}$, combined with deeper capture fractions as shown in Figure 1 where a dynamic gas test demonstrates a working capacity of $2.7 \mathrm{~mol} / \mathrm{kg}$ (NASEM, 2019). These two metrics combine to enable significant cost savings of DAC. Mosaic's nearterm goal is development of a high capacity, high efficiency sorbent material that can enable $300 \mathrm{~kg} \mathrm{CO}$ captured $/ \mathrm{kg}$

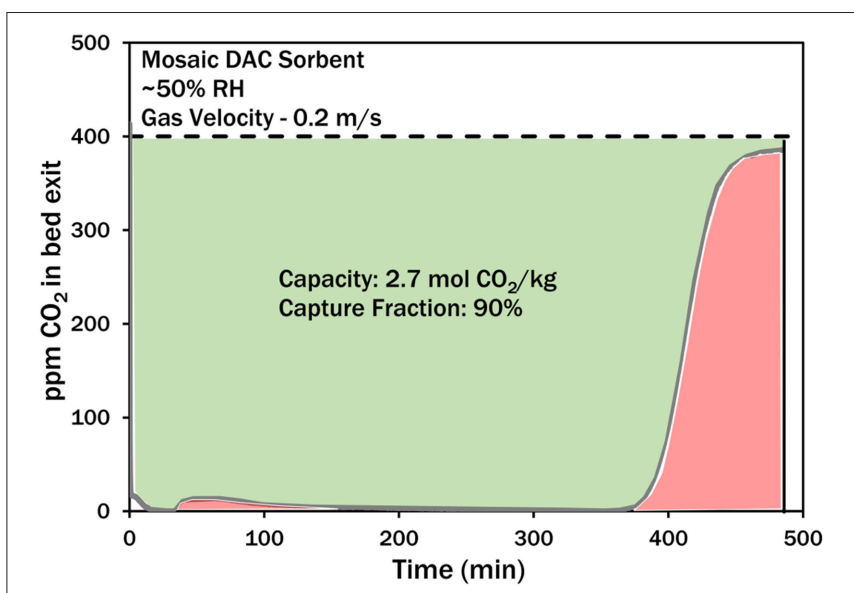

FIGURE 1 | Performance of Mosaic's DAC solid sorbent under 400 ppm $\mathrm{CO}_{2}$ in air, $\sim 25^{\circ} \mathrm{C}$ and $40-50 \% \mathrm{RH}$. Shaded areas are included to guide the eye, with green corresponding to $\mathrm{CO}_{2}$ that is retained by the material and red corresponding to $\mathrm{CO}_{2}$ that "slips" through the bed uncaptured.

sorbent over its life, with long-term goals of $>1,000 \mathrm{~kg} \mathrm{CO}_{2}$ captured $/ \mathrm{kg}$ sorbent. However, rather than focus on specific material performance, the following discussion highlights the cascading effects a high-capacity, high-performance sorbent can yield for DAC separations.

The impact of capture fraction, the percentage of $\mathrm{CO}_{2}$ entering the system which is captured by the sorbent, has a fairly straightforward impact on CapEx and OpEx. As the system capture fraction rises, less air is required to be moved in order to capture a given amount of $\mathrm{CO}_{2}$. Since the concentration of $\mathrm{CO}_{2}$ in air is so low, small changes in capture fraction translate into large differences in air handling required to capture a ton of $\mathrm{CO}_{2}$. As Figure 2 shows, increasing the capture fraction from 60 to $80 \%$ reduces air handling requirements by $\sim 500,000 \mathrm{~m}^{3} /$ ton $\mathrm{CO}_{2}$. This means that fans can be sized smaller, lowering CapEx, and will require less energy (lower OpEx) to operate due to their smaller size. For simplicity, using the $6 / 10^{\text {ths }}$ power law engineering rule of thumb, this would lead to a CAPEX reduction of $\sim 25 \%$. Furthermore, reducing the air flow will result in a reduction in pressure drop across the contactor further lowering OpEx. Or for a given system design, a higher capture fraction results in a higher throughput of $\mathrm{CO}_{2}$, again resulting in a lower capture cost per ton $\mathrm{CO}_{2}$.

Higher capacity has more extensive effects on CapEx and OpEx than capture efficiency. If the sorbent can hold more $\mathrm{CO}_{2}$ per $\mathrm{kg}$ of sorbent then less material is needed for a given amount of $\mathrm{CO}_{2}$. Taking a 50\% increase in sorbent capacity, again invoking the $6 / 10^{\text {ths }}$ rule for simplicity, results in a $35 \%$ reduction in CapEx. This has cascading benefits as fewer contactors are needed, reducing system size and thus capital required, as well as reducing regeneration energy requirements as less material will need to be heated/cooled during each adsorption/desorption cycle of the sorbent and less heat will be lost through the parasitic heat loads of sorbent and contactor sensible heating. Beyond 


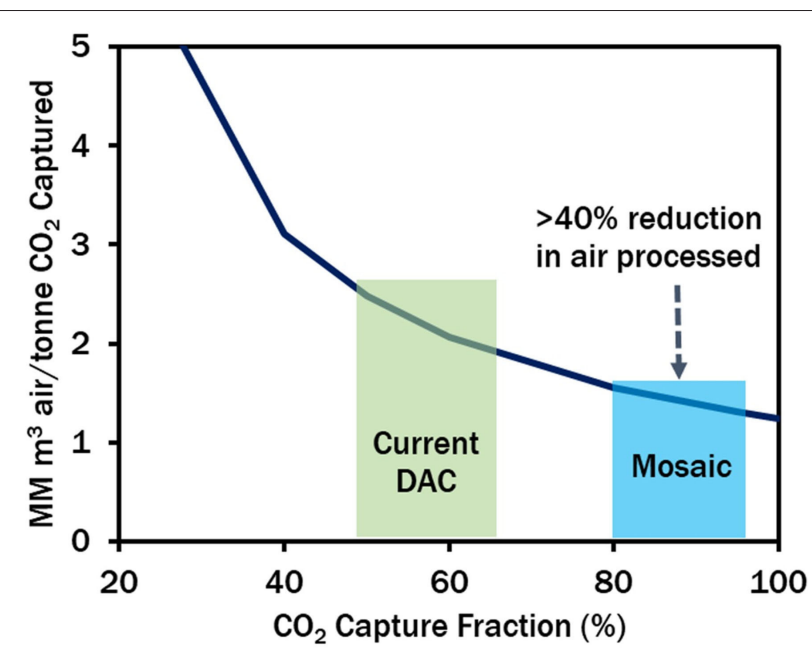

FIGURE 2 | Representation of the air required (in millions of $\mathrm{m}^{3}$ ) to capture 1 tonne of $\mathrm{CO}_{2}$ as a function of capture fraction in a DAC process. Current technologies operate under low capture fraction regimes, whereas Mosaic's efficient sorbent technology can reduce required air handling $>40 \%$ depending upon ultimate performance under process conditions.

these CapEx and OpEx savings, higher capacities can also extend the useful life of the sorbent material because the sorbent will be cycled less often. Just as if you drive your car fewer miles per year, your tires last longer, if you cycle your sorbent less often, the sorbent will last longer, which lowers periodic sorbent bed replacement costs.

These cascading effects of higher capacity and capture fraction on driving down CapEx and OpEx have dramatic impacts on the global DAC deployment. Looking solely at the number of DAC systems, doubling sorbent capacity drops the number of systems required by $50 \%$. Reexamining our earlier example, the number of systems needed to address current annual emissions drops from 10 million to 5 million. And Mosaic has demonstrated capacities in lab environments which can achieve three times the NASEM moderate case capacity, which would mean the number of systems can be halved again, down to $2.5 \mathrm{M}$, or $75 \%$ below current projections. The savings in capital expenditures, energy requirements, and land resource requirements are substantial at these levels of system reductions. In addition to being much more feasible to achieve, the increased $\mathrm{CO}_{2}$ captured per system also drops the cost of capture, enabling broader adoption of DAC as costs drop below the level of some existing government incentives, such as California's Low Carbon Fuel Standard, and global carbon credit markets, allowing businesses to do what is right for both their profitability and improve the ongoing health of the planet.

\section{WHAT IS NEEDED?}

There are three major areas which, with additional focus and support, can make the largest impact on the nascent CDR economy. These areas, broadly speaking, are enabling supply, increasing demand, and coordination across the CDR landscape.
Tackling the first area, enabling supply, is critical to ensuring companies can focus on developing and deploying the core technologies and solutions needed to enable CDR. The work on enabling supply must first be focused on infrastructure. In the case of DAC, if an industry the size of the auto industry is needed, where are the building materials for systems going to come from? Where will the chemicals needed for adsorbents come from? Do we have the labor and skills necessary to build, install, and operate these systems? Once captured, where is the infrastructure for transporting and storing $\mathrm{CO}_{2}$ ? These questions point to a more centralized and broadly available infrastructure solution set, which is a role where government can best be leveraged, such as in the recently enacted Bipartisan Infrastructure Deal (Calma, 2021). While government can help financially with subsidies and investments in new technologies to ensure a meaningful number of technologies are developed, a more substantial impact can be achieved through establishing infrastructure so that each technology solution has a standardized set of downstream assumptions to work with, thus ensuring companies can focus on their core challenge of building, scaling, and deploying their CDR solution rather than spending resources on plugging into the broader infrastructure.

Although having governments subsidize CDR is initially a necessary and helpful activity, long-term businesses must be built to exist outside of government assistance. To increase demand for CDR solutions, companies and organizations stepping forward to continue purchasing carbon from verified projects will create the true market needed to allow CDR to grow. The continued support of corporate leaders in this space, such as exemplified in recent announcements by Swiss Re, Shopify, and Microsoft, is necessary in establishing this demand (Clancy, 2021). This idea can even be expanded for small- and midsize companies through creating a type of group purchasing organization for these smaller, eco-conscious companies to buy into early-stage carbon removal projects. Broadening the accessibility and momentum of these early agreements will broaden and democratize CDR solutions. The corporate leaders buying small amounts of carbon now at high prices accelerates development and lowers future capture costs such that when the bulk of organizations are implementing internal carbon taxes and buying carbon offsets, then CDR solutions are available at prices which make investment in CDR solutions an easy decision for every organization.

Finally, given the enormity of addressing the billions of tons needed by CDR solutions, multiple approaches will be necessary. It is highly unlikely there will be one "silver bullet" approach that can be scaled quickly enough. As such, we should construct systems and awards to foster the success of multiple approaches. As multiple companies come forth with CDR solutions, an overarching cooperative approach and framework is needed to ensure companies are learning from each other and deploying successful solutions as quickly as possible. By leveraging the collective knowledge, identifying opportunities which can greatly benefit from one CDR solution over another, and collaborative supervision to ensure consistent metrics across CDR solutions, the CDR industry can expand faster than any one company could alone. 


\section{CONCLUSION}

The growing climate challenge posed by carbon dioxide emissions will require several CDR solutions to reach massive scales to remove $\mathrm{CO}_{2}$ from the atmosphere. One of these CDR solutions, direct air capture, will need tens of millions of systems to address the billions of tons of $\mathrm{CO}_{2}$ already in the atmosphere-roughly equivalent with building an industry the size of the automotive industry in the next decade. While first generation systems are needed now to kickstart the process, focusing on sorbent material development, specifically on increasing sorbent capacity and capture efficiency, enables cascading process improvements that can cut the number of systems-and associated materials, land, and energy-needed by an order of magnitude. This will enable faster rollout and more efficient use of capital and resources in addressing carbon emissions. The major challenges around establishing supply chains at the scales needed and continuing to grow demand, especially in the early stages of CDR, will require massive levels of coordination. Collaboration within and between governments, corporations, and the industry itself will be required to ensure that new developments, like this and so many other new technologies, can be deployed in time to mitigate the growing climate challenge. Scientists have been highlighting the impacts and scale of carbon emissions and climate change for some time

\section{REFERENCES}

Beuttler, C., Charles, L., and Wurzbacher, J. (2019). The role of direct air capture in mitigation of anthropogenic greenhouse gas emissions. Front. Clim. 1:10. doi: $10.3389 /$ fclim. 2019.00010

Calma, J. (2021). The Infrastructure Deal Could Create Pipelines for Captured CO2. The Verge. 2021. Available online at: https://www.theverge.com/ 2021/8/3/22606395/pipeline-battle-co2-removal-carbon-capture-bipartisaninfrastructure (accessed September 25, 2021).

Carbon Engineering (2020). Oxy Low Carbon Ventures, Rusheen Capital Management Create Development Company 1PointFive to Deploy Carbon Engineering's Direct Air Capture Technology. Available online at: https://carbonengineering.com/news-updates/new-development-company1pointfive-formed/ (accessed September 28, 2021).

Carbon180 (2021). The DAC MAPP. Available online at: https://carbon180.org/ dac-mapp (accessed September 30, 2021).

Clancy, H. (2021). What You Should Know about Carbon Removal Purchase Agreements. Oakland, CA: GreenBiz. Available online at: https://www.greenbiz. com/article/what-you-should-know-about-carbon-removal-purchaseagreements (accessed September 24, 2021).

Climeworks (2021). Climeworks Website. Available online at: https://climeworks. com/orca (accessed September 28, 2021).

Deutz, S., and Bardow, A. (2021). Life-cycle assessment of an industrial direct air capture process based on temperature-vacuum swing adsorption. Nat. Energy 6, 203-213. doi: 10.1038/s41560-020-00771-9

Energy Futures Initiative (2019). Clearing the Air: A Federal RD\&D Initiative and Management Plan for CO2 Removal Technologies. Troubled Lands, no. September: 29-54. Washington, DC: Energy Futures Initiative.

IEA (2019). Putting CO2 to Use. Paris: IEA. Available online at: https://www.iea. org/reports/putting-co2-to-use (accessed September 28, 2021).

IPCC (2021). Climate Change 2021: The Physical Science Basis. Contribution of Working Group I to the Sixth Assessment Report of the Intergovernmental Panel on Climate Change. https://www.google.com/search?sxsrf= AOaemvIZ83aP8ydOEcxj7ihvXgaGI4RRiw:1640245434918 Geneva: IPCC. now, and there is finally widespread momentum within, and between, scientific, public and private sectors that we need to keep accelerating. This challenge is a seminal moment for our generation-the time to work together on it is now.

\section{DATA AVAILABILITY STATEMENT}

The original contributions presented in the study are included in the article/supplementary material, further inquiries can be directed to the corresponding author.

\section{AUTHOR CONTRIBUTIONS}

Both authors have contributed equally to the work and approved it for publication.

\section{ACKNOWLEDGMENTS}

The authors would like to thank the editors of this journal for the invitation to submit an article to the Negative Emission Technology section of Frontiers in Climate, and additionally thank Stripe for funding the open-access fees on this critical research topic. We would also like to thank the reviewers of this article.

Keith, D. W., Holmes, G., Angelo, D. S., and Heidel, K. (2018). A process for capturing CO2 from the atmosphere. Joule 2, 1573-1594. doi: 10.1016/j.joule.2018.05.006

LBNL (2021). Frequently Asked Global Change Questions. Available online at: https://cdiac.ess-dive.lbl.gov/pns/faq.html (accessed September 28, 2021).

Leibling, K., McQueen, N., Pisciotta, M., and Wilcox, J. (2021). Direct Air Capture: Resource Considerations and Costs for Carbon Removal. World Resources Institute. Available online at: https://www.wri.org/insights/direct-air-captureresource-considerations-and-costs-carbon-removal (accessed September 28, 2021).

McDonald, T. M., Lee, W. R., Mason, J. A., Wiers, B. M., Hong, C. S., and Long, J. R. (2012). Capture of carbon dioxide from air and flue gas in the alkylamineappended metal_organic framework mmen-Mg 2 (Dobpdc). J. Am. Chem. Soc. 134, 7056-7065. doi: 10.1021/ja300034j

McDonald, T. M., Mason, J. A., Kong, X., Bloch, E. D., Gygi, D., Dani, A., et al. (2015). Cooperative insertion of CO2 in diamine-appended metal-organic frameworks. Nature 519, 303-308. doi: 10.1038/nature14327

NASEM (2019). Negative Emissions Technologies and Reliable Sequestration. Negative Emissions Technologies and Reliable Sequestration: A Research Adgenda. Washington, DC: The National Academies Press.

NOAA (2021). Carbon Dioxide Peaks near 420 Parts per Million at Mauna Loa Observatory. Available online at: https://research.noaa.gov/article/ArtMID/ 587/ArticleID/2764/Coronavirus-response-barely-slows-rising-carbondioxide (accessed September 28, 2021).

Peters, A. (2021). The Carbon Removal Industry Needs to Grow to Be the Size of the Oil and Gas Industry. New York, NY: Fast Company. Available online at: https:/www.fastcompany.com/90657209/the-carbon-removal-industryneeds-grow-to-be-the-size-of-the-oil-and-gas-industry (accessed September 28, 2021).

Sholl, D. S., and Lively, R. P. (2016). Seven chemical separations to change the world. Nature 532, 6-8. doi: 10.1038/532435a

UNFCCC (2021). United Nations Framework Convention on Climate Change: Nationallydetermined Contributions Under the Paris Agreement. Bonn: UNFCCC. 
US Department of Transportation (2021). Annual US Motor Vehicle Production and Domestic Sales, Bureau of Transportation Statistics. Available online

at: https://www.bts.gov/content/annual-us-motor-vehicle-productionand-factory-wholesale-sales-thousands-units (accessed September 28, 2021).

Wright, T. P. (1936). Factors affecting the cost of airplanes. J. Aeronaut. Sci. 3, 122-128. doi: $10.2514 / 8.155$

Author Disclaimer: Opinions and calculations presented within this article are the views and work of JCH and GBW.

Conflict of Interest: The authors are employees of Mosaic Materials, Inc.
Publisher's Note: All claims expressed in this article are solely those of the authors and do not necessarily represent those of their affiliated organizations, or those of the publisher, the editors and the reviewers. Any product that may be evaluated in this article, or claim that may be made by its manufacturer, is not guaranteed or endorsed by the publisher.

Copyright (c) 2022 Husk and Wenz. This is an open-access article distributed under the terms of the Creative Commons Attribution License (CC BY). The use, distribution or reproduction in other forums is permitted, provided the original author(s) and the copyright owner(s) are credited and that the original publication in this journal is cited, in accordance with accepted academic practice. No use, distribution or reproduction is permitted which does not comply with these terms. 